\title{
Not Knowing a Cat is a Cat: Analyticity and Knowledge Ascriptions
}

\author{
J. Adam Carter, Martin Peterson and Bart van Bezooijen
}

\begin{abstract}
It is a natural assumption in mainstream epistemological theory that ascriptions of knowledge of a proposition $p$ track strength of epistemic position vis-à-vis $p$. It is equally natural to assume that the strength of one's epistemic position is maximally high in cases where $p$ concerns a simple analytic truth (as opposed to an empirical truth). For instance, it seems reasonable to suppose that one's epistemic position vis-à-vis "a cat is a cat" is harder to improve than one's position vis-à-vis "a cat is on the mat", and consequently, that the former is at least as unambiguous a case of knowledge as the latter. The current paper, however, presents empirical evidence which challenges this intuitive line of reasoning. Our study on the epistemic intuitions of hundreds of academic philosophers supports the idea that simple and uncontroversial analytic propositions are less likely to qualify as knowledge than empirical ones. We show that our results, though at odds with orthodox theories of knowledge in mainstream epistemology, can be explained in a way consistent with Wittgenstein's remarks on 'hinge propositions' or with Stalnaker's pragmatics of assertion. We then present and evaluate a number of lines of response mainstream theories of knowledge could appeal to in accommodating our results. Finally, we show how each line of response runs into some prima facie difficulties. Thus, our observed asymmetry between knowing "a cat is a cat" and knowing "a cat is on the mat" presents a puzzle which mainstream epistemology needs to resolve.
\end{abstract}

\section{INTRODUGTION}

A natural assumption in epistemological theory is that knowledge-ascriptions should, in some suitably specified sense, track strength of epistemic position. There is considerable debate about whether one's epistemic position is determined exclusively by epistemic factors or also partly by pragmatic factors (e.g. Fantl and McGrath 2009). It is also a matter of dispute between contextualists (e.g. DeRose 1992; 2009) and subject-sensitive invariantists (e.g. Stanley 2005; Hawthorne 2004) just whose epistemic position should matter for knowledge-ascriptions: the attributor's epistemic position or the epistemic position of the subject of the attribution? Despite these dividing lines, all sides agree that in cases of first-person knowledge 
attributions - where the attributor and the subject of the attribution are the same ${ }^{1}$ - then whether a subject $\mathrm{S}$ counts as knowing a proposition $p$ is going to be a function of the strength of S's epistemic position vis-à-vis $p .^{2}$

That said, a separate but also very natural assumption is that S's epistemic position with respect to simple analytic truths is going to be maximally high. It is, after all, hard to see how one's epistemic strength vis-à-vis such positions could ever be improved upon ${ }^{3}$. Furthermore, it doesn't seem that whether we would take ourselves as knowing "A cat is a cat" would be sensitive to shifting stakes, even if (as contextualists and subject-sensitive invariantists claim) our willingness to ascribe knowledge of other kinds of non-analytic (empirical) propositions is inclined to vary across such practical circumstances, where stakes are shifted. An obvious explanation for why it seems that our epistemic position vis-à-vis simple analytic truths could not be improved is that it is already as good as it could be. These are propositions that we know if we know anything at all.

A very simple and well-known picture follows from the combination of (i) the assumption that whether one counts as knowing that $p$ (in first-person knowledge ascriptions) is a function of the strength of the subject's epistemic position vis-à-vis $p$; and (ii) that when $p$ is a simple analytic truth, the strength of one's epistemic position is going to be maximally high. The resulting picture is one that predicts, ceteris paribus, that individuals attribute knowledge of simple analytic truths to themselves to at least as great an extent as any other propositions ${ }^{4}$. That is, for some simple analytic truth $a$, and corresponding empirical truth $e$, you should be at least as inclined to ascribe knowledge to yourself of $a$ as $e$.

In the next three sections, Sections 2, 3 and 4, we present two empirical studies of epistemic intuitions reported by academic philosophers who hold a $\mathrm{PhD}$ in philosophy and speak English as their first language. The surveys support a surprising subversion of the picture outlined above. In particular, the results show that simple and uncontroversial analytic truths are less likely to be claimed to be known by respondents than empirical truths.

After detailing the results of our experimental studies, we show in Section 5 that, although our empirical results pose some prima facie difficulties received assumptions in

\footnotetext{
1 That is, where the context of utterance and the circumstance of evaluation don't come apart.

2 An exception here is the truth-relativist about knowledge ascriptions, according to whom the epistemic position relevant to the truth of the knowledge-ascription is that of the assessor's. See here MacFarlane (2005, 2008).

${ }^{3}$ For example, if you already accept that bachelors are, in virtue of the meaning of 'bachelor', unmarried men, you are not going to have any further reason to accept this proposition when you hear that person $\mathrm{A}$ is a bachelor and is unmarried and male.

${ }^{4}$ Of course, the orthodox view concerns what we know, and only indirectly how we attribute knowledge. However, and as will be relevant in what follows, (defeasible) evidence against the attribution patterns we'd expect in light of the orthodox theory is at least indirectly is at tension with the orthodox theory.
} 
mainstream thinking in epistemology, there is nonetheless some philosophical rationale for our 'heterodox' results, and in particular, in Wittgenstein's account of the structure of reasons in On Certainty and Stalnaker's work on the pragmatics of assertion. After noting these kinds of precedents for our experimental results, we evaluate a number of responses defenders of mainstream theories of knowledge could appeal to in accommodating them. As we shall see, each line of response runs into difficulties.

\section{HYPOTHESIS AND METHOD}

In order to test whether first-person propositional knowledge ascriptions (hereafter, knowledge ascriptions) depend on the informational content, and thus not just strength of the subject's epistemic position vis-à-vis the target position, we decided to investigate the following hypothesis:

$\mathrm{H}$ : Philosophers are more willing to acknowledge that they know $p$ if $p$ is an empirical truth (that meets the condition for knowledge) than if $p$ is a simple and uncontroversial analytic truth.

The reason why we are primarily interested in simple and uncontroversial analytic truths is that complex analytic truths may not meet the conditions for knowledge. For instance, the subject may not be able to believe or acquire sufficient warrant for, say, highly complex mathematical truths.

We are of course aware that the distinction between analytic and empirical propositions is one of the most hotly contested distinctions in philosophy. ${ }^{5}$ We shall make no attempt to present a precise account of this distinction here. Quine (1951) taught us that this is no easy task. However, for our hypothesis to hold true it does not matter exactly how the distinction is spelled out. All that matters is that there is some non-random pattern that relates knowledge ascriptions to paradigmatic examples of analytic and empirical truths.

We take the following to be paradigmatic examples of simple and uncontroversial analytic truths: "All squares are four-sided", "All vixens are female", and "All bachelors are unmarried". Propositions such as "The cat is on the mat", "There are more than three vixens in the world", and "The planet Earth more closely resembles a sphere than a flat surface" are

\footnotetext{
${ }^{5}$ For a sustained recent discussion here, see Russell (2011).
} 
paradigmatic examples of empirical truths. ${ }^{6}$

If a simple and uncontroversial analytic truth is less likely to be claimed as known than some empirical truth the respondent can be assumed to have knowledge about (e.g., "The planet Earth more closely resembles a sphere than a flat surface"), then this furnishes -- contra orthodoxy - defeasible prima facie support that informational content, and not just strength of epistemic position, are taken as relevant to whether one knows. For ease of reference, let's refer to such a view as a 'content-dependent' account of knowledge. According to this view, the strength of epistemic position does not uniformly determine whether one satisfies knowledge conditions.

In order to test hypothesis $\mathrm{H}$, we performed two studies. It is worth stressing that the results in both studies were very similar.

In the first study, respondents were presented with eighteen 7-point Likert-type items ranging from 1 ("I strongly disagree") to 7 ("I strongly agree") in an online questionnaire (one question per time, with no possibility to go back and alter previous answers). All questions were of the following structure:

To what extent do you take yourself to know the following statement:

"All bachelors are unmarried."

$[1--7]$

\footnotetext{
${ }^{6}$ An anonymous reviewer has pointed out that it is not certain that our examples of simple and uncontroversial analytic truths were perceived as such by the respondents. For instance, in response to "All vixens are female" someone could say: "Sounds right but I don't really remember what a vixen is." We agree that this is indeed a possibility, but we would like to make two points in response to this claim. First, the same comment could also be made about our list of empirical propositions. For instance, in response to the empirical truth "World War II occurred" someone could object say: "Sounds right but I don't really remember what World War II was". This just illustrates that one can never be sure how responds interpret a survey question. The second point, which is more important, is that what ultimately matters for the truth of our hypothesis is not whether our list of propositions were actually perceived as analytic or not; what matters is that they are analytic/empirical. We are not testing the hypothesis "Philosophers are more willing to acknowledge that they know $\mathrm{p}$ if $\mathrm{p}$ is perceived as an empirical truth than if $\mathrm{p}$ is perceived as an analytic truth." The hypothesis we are testing is whether philosophers are more willing to acknowledge that they know $\mathrm{p}$ if $\mathrm{p}$ is an empirical truth than if $\mathrm{p}$ is an analytic truth (of the right kind). The only defense we can give for the claim that our test propositions are of the right kind is that they are based on standard examples given in textbooks and academic journals. No psychological measure can help us to determine whether a proposition is analytic or empirical. That said, the matter of whether a truth is perceived as analytic is of course relevant to what can be reasonably inferred from our hypothesis about the truth of orthodox theories of knowledge. We are sensitive to this point in the discussion section.
} 
To what extent do you take yourself to know the following statement:

"There is at least one bachelor in England."

$[1--7]$

Data were collected from 175 participants in one week in June 2014. All participants were recruited via two email lists for academic philosophers in the UK (Philos-L) and the Netherlands (Filos-NL). Both lists are primarily used for advertising jobs, upcoming conferences and other events of interest to academic philosophers. Since we were particularly interested in intuitions reported by experts, and because we know from earlier studies that one's epistemic intuitions sometimes depend on one's native language, we initially excluded responses from participants who did not have a $\mathrm{PhD}$ in philosophy or were not native speakers of the English language. ${ }^{7}$ The responses from the remaining 57 respondents, who held a $\mathrm{PhD}$ in philosophy and whose first language was English, were then compared with expert responses. Participants were also asked to provide information about their gender, participation in prior research on this topic, and which philosophical tradition they felt most closely affiliated with. We excluded thirteen participants who recalled taking part in our earlier studies.

TABLE 1.

List of propositions included in the first study.

\begin{tabular}{|c|c|c|}
\hline Proposition & empirical & analytic \\
\hline 1a. Barack Obama is President of the United States of America & $\mathrm{X}$ & \\
\hline 2a. Some humans have squaredanced & $\mathrm{X}$ & \\
\hline 3a. Ice can be found on the surface of Antartica & $\mathrm{X}$ & \\
\hline 4a. World War II occurred & $\mathrm{X}$ & \\
\hline 5a. Napoleon Bonaparte was French and not currently the leader of & $\mathrm{X}$ & \\
\hline \multicolumn{3}{|l|}{ Russia } \\
\hline 6a. There is at least one bachelor in England & $\mathrm{X}$ & \\
\hline 7a. Julius Caesar was assassinated & $\mathrm{X}$ & \\
\hline 8a. There are more than three vixens in the world & $\mathrm{X}$ & \\
\hline 9a. The planet Earth more closely resembles a sphere than a flat surface & $\mathrm{X}$ & \\
\hline
\end{tabular}

${ }^{7}$ See [SUPPRESSED REFERENCE]. 
1b. Barack Obama does not both exist and not exist

2b. All squares are four-sided

3b. Everything that is ice is frozen $\quad \mathrm{X}$

4b. War is war $\quad \mathrm{X}$

5b. 2 does not equal 1 , and 1 does not equal $2 \quad \mathrm{X}$

6b. All bachelors are unmarried ${ }^{8} \quad$ X

7b. No one who was assassinated is still alive $\quad \mathrm{X}$

8b. All vixens are female $\quad \mathrm{X}$

9b. Spheres are not flat surfaces $\quad \mathrm{X}$

\section{RESULTS OF THE FIRST STUDY}

We first checked whether data were normally distributed, which turned out not to be the case. ${ }^{9}$ We therefore analysed data by using non-parametric Wilcoxon signed-rank test procedures. This test procedure checks whether a participant reports an identical, higher or lower score for each 'pair' of empirical and analytic propositions, where what were compared in our analysis were the $\mathrm{a}$ and $\mathrm{b}$ version of each numbered item: so la was compared with $1 \mathrm{~b}$ (but not with $2 \mathrm{~b}$ or $3 \mathrm{~b}$, for example), $2 \mathrm{a}$ was compared with $2 \mathrm{~b}$, and so on. If the scores are identical, i.e. if the respondent makes the same judgement about the empirical and analytic propositions, then that counts as a tie. A higher score on the second measure (the empirical proposition) is called a positive rank, and a lower score on the second measure is a negative rank. ${ }^{10}$

TABLE 2.

Results for the Wilcoxon signed-rank test for the sets of empirical and analytic propositions $(n$ $=175)$.

\section{Degree in Philosophy}

\footnotetext{
${ }^{8}$ One potential worry about this particular statement is that it is often used as an example of an analytic truth, and accordingly, some philosophers familiar with the example might find they have a tendency to refrain from self-attributing knowledge in the case on the basis of an antecedent skepticism about analytic truths more generally. While we grant this possibility, we want to add that ascribing to oneself knowledge in this case is not to ascribe to oneself knowledge of the proposition as an analytic truth. One could for instance, antecedently reject the philosophical position ordinarily associated with rationalist philosophers and still maintain that one knows a statement of this form. Thanks to an anonymous referee for raising this point.

${ }^{9}$ As many readers of this paper know, the normal or (Gaussian) distribution is one of the most widely studied statistical distributions. It has a number of neat mathematical properties and looks like a bell curve. See e.g. Krickeberg (1965: 89) for a helpful introduction and discussion.

10 The choice of what counts as a negative or positive rank is arbitrary in this study. We simply decided to use non-empirical propositions as the baseline for making comparisons. If we would have used empirical propositions as the baseline, the test statistics would have been reversed.
} 


\begin{tabular}{lccc}
\hline & No PhD & PhD & \\
\hline English not first & $n=38 ; Z=1.11 ; r=.18$ & $n=46 ; Z=1.42 ; ; r=.21$ & $n=91$ \\
language & $n=34 ; Z=2.43^{*} ; r=.41$ & $n=57 ; Z=1.76^{*} ; r=.23$ & $n=84$ \\
English first & $n=72$ & $n=103$ & $\mathcal{N}=175$ \\
language & $n$ & & \\
\hline${ }^{*}=p<.05$ & & &
\end{tabular}

As can be seen in Table 2, we found statistically significant $(p<.05)$ differences between empirical and analytic propositions for respondents whose first language is English and hold a $\mathrm{PhD}$ in philosophy, as well as in the group of respondents whose first language is English and do not hold a $\mathrm{PhD}$ in philosophy. However, unlike in the second study reported in the next section, this difference was not found for non-native speakers of English, regardless whether they had a PhD in philosophy or not. A possible explanation for this difference is that the number of participants was smaller in the first study.

\section{THE SECOND STUDY}

The main difference between the first and second studies was the trigger question presented to participants. Instead of asking "To what extent do you take yourself to know the following statement", the trigger question in the second study was the following:

"To what extent do you agree that the following proposition qualifies as knowledge".

These two trigger questions differ in important respects. Although you may not know that $p$, it may very well be the case that $p$ qualifies as knowledge in your or some other epistemic community. However, as we explain below, the truth of hypothesis $\mathrm{H}$ does not hinge of which of the two trigger questions is used.

Data for the secondary study were collected from 408 respondents in two weeks in June 2013. (So the second study was actually performed before the first. We call this the "second" study because of some minor imperfections in the data collection described below.) As in the first study, all participants were recruited via email lists for academic philosophers. Out of 408 respondents, 136 held a $\mathrm{PhD}$ in philosophy and spoke English as their first language. 
After we had collected data we discovered that one analytic proposition had not been correctly formulated in the online questionnaire. ${ }^{11}$ Moreover, since we needed to compare pairs of empirical and analytic propositions, this meant that one empirical proposition also had to be dropped. Finally, we also realized that one proposition seemed to have been too similar to another one and probably confused the participants. ${ }^{12}$ We therefore decided to omit also that question from the dataset. This left us with ten propositions, of which five were empirical truths and five analytic ones. The decision to drop some of the questions did not affect the overall conclusion of the study.

TABLE 3.

List of propositions included in the second study.

\begin{tabular}{|c|c|c|}
\hline Proposition & empirical & analytic \\
\hline 1. Water is $\mathrm{H} 2 \mathrm{O}$. & $\mathrm{X}$ & \\
\hline 2. The earth isn't flat. & $\mathrm{X}$ & \\
\hline $\begin{array}{l}\text { 3. Water boils at } 100 \text { degrees Celsius or } 212 \text { degrees Fahrenheit (at } \\
\text { normal atmospheric pressure). }\end{array}$ & $\mathrm{X}$ & \\
\hline 4. A cat is not a dog. & $\mathrm{X}$ & \\
\hline 5. The country France is in Europe. & $\mathrm{X}$ & \\
\hline 6. Invisible objects aren't visible. & & $\mathrm{X}$ \\
\hline $\begin{array}{l}\text { 7. One can overcome the problem of global warming, if one does } \\
\text { something that solves the problem }\end{array}$ & & $\mathrm{X}$ \\
\hline $\begin{array}{l}\text { 8. Cancer would no longer kill millions of people, if one took away all of } \\
\text { its causes and cured all those afflicted by it }{ }^{13} \text {. }\end{array}$ & & $\mathrm{X}$ \\
\hline 9. A hexagon has either a finite or an infinite number of sides. & & $\mathrm{X}$ \\
\hline 10. There either is or isn't a largest prime number. & & $\mathrm{X}$ \\
\hline
\end{tabular}

11 "U.S. President Obama is either above 6 feet tall or below 6 feet tall" was intended to be an analytic proposition. But it is of course possible that Mr Obama is exactly 6 feet tall. The correct formulation would have been: "U.S. President Obama is either less than 6 feet tall or at least 6 feet tall".

12 Both these questions were about water: "Water is H2O" and "Water is water". The second appeared closely after the first, which probably had unforeseen effects on the judgements reported by respondents.

${ }^{13}$ While we regard (7) and (8) as trivial, given that solving a problem is trivially a way of overcoming a problem, and given that the efficacy of something is trivially undermined by removing its causes and effects, we appreciate that these questions might, in virtue of their length (and subjunctive moods) potentially seem more substantive. Thanks to an anonymous referee for raising this point. 
As in the first study, we analysed data by using non-parametric Wilcoxon signed-rank test procedures. Within our sample of 136 native English-speaking philosophers, about half gave a positive overall rank to empirical propositions $(Z=4.85 ; p<.001, r=.41$; see Table 2 for results). About one quarter gave a negative overall rank to analytic propositions, and one quarter reported a tie.

\section{TABLE 4.}

Results for the Wilcoxon signed-rank test for the sets of empirical and analytic propositions $(n$ $=136)$.

\begin{tabular}{|c|c|c|c|c|c|c|}
\hline & $\mathrm{N}$ & Mean Rank & Sum of Ranks & $z$ & $p$ & $r$ \\
\hline Negative Ranks & 32 & 36,78 & 1177,00 & 4.85 & .000 & .41 \\
\hline Positive Ranks & 70 & 58,23 & 4076,00 & & & \\
\hline Ties & 34 & & & & & \\
\hline Total & 136 & & & & & \\
\hline
\end{tabular}

We also made pairwise comparisons between each pair of propositions. The difference we found between the two sets of propositions was also observed in these pairwise comparisons. See Table 5.

The pairwise comparisons show that respondents were consistently more willing to claim knowledge of empirical propositions than of corresponding analytic ones. In other words, the difference between the two sets of propositions does not result from extreme scores on a smaller subset of propositions.

There was only one pair of propositions for which we did not find a positive rank. (See Table 5, Q1 - Q6). A possible explanation could be that these questions were the first presented to participants, at a point at which they were still forming their thoughts about the questions. They therefore gave more or less neutral responses to the first question. In future studies one could include some dummy questions before the actual questions are presented to participants.

TABLE 5.

Results for the Wilcoxon signed-rank test procedures for pairs of items $(n=136)$.

\begin{tabular}{llllll}
\hline & N & Mean Rank & Sum of Ranks & Z & $r$ \\
\hline Q1-Q6 & & & & & \\
Negative ranks & 32 & 24,36 & 779,50 & .326 & .02 \\
& & & 9 & &
\end{tabular}




\begin{tabular}{|c|c|c|c|c|c|}
\hline Positive ranks & 22 & 32,07 & 705,50 & & \\
\hline Ties & 82 & & & & \\
\hline Total & 136 & & & & \\
\hline \multicolumn{6}{|l|}{$Q^{2}-Q^{7}$} \\
\hline Negative ranks & 16 & 25.63 & 410,00 & $5.01^{*}$ & .43 \\
\hline Positive ranks & 55 & 39,02 & 2146,00 & & \\
\hline Ties & 65 & & & & \\
\hline Total & 136 & & & & \\
\hline \multicolumn{6}{|l|}{$\mathrm{Q}^{3-\mathrm{Q}^{8}}$} \\
\hline Negative ranks & 27 & 22,00 & 594,00 & $3.59^{*}$ & .31 \\
\hline Positive ranks & 41 & 42,73 & 1752,00 & & \\
\hline Ties & 68 & & & & \\
\hline Total & 136 & & & & \\
\hline \multicolumn{6}{|l|}{$\overline{Q^{4-}-Q^{9}}$} \\
\hline Negative ranks & 17 & 12,88 & 219,00 & $4.31^{*}$ & .37 \\
\hline Positive ranks & 35 & 33,11 & 1159,00 & & \\
\hline Ties & 84 & & & & \\
\hline Total & 136 & & & & \\
\hline \multicolumn{6}{|l|}{ Q5-Q10 } \\
\hline Negative ranks & 21 & 19,38 & 407,00 & $4.84^{*}$ & .42 \\
\hline Positive ranks & 48 & 41,83 & 2008,00 & & \\
\hline Ties & 67 & & & & \\
\hline Total & 136 & & & & \\
\hline
\end{tabular}

$*=p<.001$

In the second study, it is not only philosophers who hold a $\mathrm{PhD}$ in philosophy and speak English as their first language that are more willing to ascribe knowledge to empirical propositions than to simple and uncontroversial analytic ones. Similar differences were found for all groups of respondents in the present study, irrespective of whether they held a $\mathrm{PhD}$ in philosophy or spoke English as their first language. That said, differences in knowledge ascriptions are influenced to a greater extent by the respondent's first language than by education in philosophy. ${ }^{14}$ As can be derived from Table 6, the effect sizes for language

\footnotetext{
${ }^{14}$ As mentioned in Section 2, we also asked participants to provide information about gender, participation in prior research on this type, and which philosophical tradition they felt most closely affiliated with. $4 \%$ said they had participated in similar studies before and $70 \%$ were sure they had not; $78 \%$ of respondents were
} 
groups differ quite a lot (effect sizes range from .56 to .57 for respondents whose first language is not English, versus effect sizes from .33 to .42 for respondents whose first language is English), while the effect sizes of people who have a $\mathrm{PhD}$ in philosophy are largely overlapping effect sizes range from .33 to .56 for respondents without a $\mathrm{PhD}$ in philosophy, and from .42 to .57 for respondents who hold a $\mathrm{PhD}$ in philosophy). These findings replicate the results of an earlier study on 776 trained philosophers performed by three of the four authors of this article. [See SUPPRESSED REFERENCE] The main finding in our earlier study was that philosophers' epistemic intuitions vary according to their linguistic background, even when all respondents are presented with the same set of questions in English. In that study we also noted some differences between what we in the present article call empirical and analytic propositions, but this effect was never studied in detail. See Table 1 in [SUPPRESSED REFERENCE].

TABLE 6.

Results for all sub-groups of respondents.

\begin{tabular}{|c|c|c|c|}
\hline \multicolumn{4}{|c|}{ Degree in Philosophy } \\
\hline & No PhD & $\mathrm{PhD}$ & \\
\hline English not first & $n=92 ; z=5.33^{* * *} ; r=.56$ & $n=101 ; z=5.72^{* * *} ; r=$ & $n=193$ \\
\hline language & & .57 & \\
\hline English first & $n=79 ; z=2.93^{*} ; r=.33$ & $n=136 ; z=4.84^{* * *} ; r=$ & $n=215$ \\
\hline language & & .42 & \\
\hline & $n=171$ & $n=237$ & $\mathcal{N}=408$ \\
\hline
\end{tabular}

\section{DISGUSSION}

Our empirical findings, though in clear tension with orthodox thinking in mainstream epistemology, nonetheless lend themselves to at least two kinds of natural philosophical explanations. We divide this discussion section into two parts. In the first part, we outline these potential explanations. In the second part, we assess the implications our experimental results have for orthodox theories of knowledge by outlining several strategies of response that

male, and 70\% identified themselves as analytic philosophers. No statistically significant correlations were found. 
could be offered on behalf of orthodox accounts of knowledge. We then show that each strategy turns up with its own problems.

\subsection{Two Philosophical Explanations of $H$}

Recall that according to hypothesis $\mathrm{H}$, philosophers are more willing to acknowledge that they know $p$ if $p$ is an empirical truth (that meets the condition for knowledge) than if $p$ is a simple and uncontroversial analytic truth.

An explanation for $\mathrm{H}$ would involve, at least, that we identify some property of simple, analytic truths not shared by empirical truths, and then provide, with reference to such a property, a principled reason for thinking that simple, analytic propositions would be less likely to be claimed as knowledge. We consider here two kinds of philosophical explanations. One is found in Wittgenstein's posthumous epistemological treatise On Certainty (1969). The other owes to Stalnaker's (1978) seminal work on the pragmatics of assertion.

Wittgenstein's project in On Certainty relies importantly on a simple observation about the structure of rational support. Put concisely, Wittgenstein's position can be stated as follows:

Structure of Reasons: For agent $S$, reason $R$ and belief $B, S$ can take $R$ as a reason to believe $B$ only if $R$ is more certain for $S$ than $B .{ }^{15}$

The key idea is that one cannot rationally support a claim by appealing to some reason less certain to one than the claim in question. ${ }^{16}$ An upshot of this account of the structure of rational support is that we can never rationally support those claims of which we are most certain. After all, we will never be more certain of any reason we could offer in favour of such claims. Wittgenstein called such claims "hinge propositions". ${ }^{17}$ Let us call a proposition HP if it has the epistemic property of being a hinge proposition, i.e. if it is such that it cannot, with

15 This straightforward idea accounts for why Wittgenstein famously found it objectionable that G.E. Moore $(1925 / 1939)$ tried to prove the existence of the external world by simply holding up his hands and saying "here is one hand, and here is another." Moore, after all, could never have been more certain he had a hand than that there was an external world, and so the former cannot be appealed to as rational support for accepting the latter.

${ }^{16}$ Cf. Wittgenstein's remark in On Certainty that: "If a blind man were to ask me "Have you got two hands?" I should not make sure by looking. If I were to have any doubt of it, then I don't know why I should trust my eyes. For why shouldn't I test my eyes by looking to find out whether I see my two hands. What is to be tested by what?" (OC, §125).

17 As Pritchard (2012: 259) puts it, "Wittgenstein is thus offering us a challenging conception of the structure of reasons, such that our reason-giving practices presuppose a class of fundamental hinge commitments which are by their nature immune to rational evaluation. The upshot of this argument is that there cannot be a satisfactory rational way of terminating the regress of reasons, since at some point in the regress one will inevitably encounter those propositions which one is most certain of - the hinge propositions - and yet these propositions by their very nature cannot be rationally supported." 
reference to the account of the structure of reasons presented here, be rationally supported by appeal to reasons of which one is more certain than these claims themselves.

Wittgenstein held that all (sufficiently simple) analytic propositions have the property of being hinge propositions ${ }^{18}$ and that just some empirical propositions, including Moore's (1939) claim that he has a hand, played the role of hinge propositions. ${ }^{19}$ Already here, a philosophical rationale for the empirical results of our survey materialises: In so far as we follow Wittgenstein ${ }^{20}$ in taking knowledge attributions to attribute rational support - viz., such that self-ascribing knowledge that $p$ involves a willingness to self-ascribe rational support for $p$, then if (i) all simple analytic truths have a property - $\mathrm{HP}$ - in virtue of which we cannot appeal to other propositions to rationally support them; and (ii) only some empirical propositions will have this property, then ceteris paribus, knowledge of simple analytic truths will be attributed to a less extent than knowledge of empirical propositions. This is effectively the hypothesis $\mathrm{H}$ our empirical results confirmed. Thus, the Wittgenstenian account of the structure of rational support is at least one kind of philosophical explanation that would predict the kinds of results our survey has registered, and which run afoul of orthodox accounts of knowledge. ${ }^{21}$

A very different kind of philosophical explanation for our results can be gleaned from Stalnaker's influential work on the pragmatics of assertion. On Stalnaker's (1978) view, the communication context is the set of live options at each point in a conversation. The role of assertion can be defined in terms of the set of live options, namely, the role of assertion is to cut down the live options and in doing so narrow the communication context. ${ }^{22} \mathrm{~A}$ proposition is a presupposition of the communication context if it is already part of the 'common ground' between the speaker and hearer. ${ }^{23}$

Asserting what is presupposed (and thus part of the common ground) is "pointless" in a communication context as it will not cut down any live options and thus will not narrow the communication context. As Stalnaker puts it, "to assert something which already presupposed

\footnotetext{
18 Take, for instance, "Invisible objects aren’t visible.” For a competent user of English, what rational support could be offered in support of this proposition, such that we are more certain of the rational support than of the proposition itself?

19 After all, many empirical propositions will have the property of being such that there are other propositions of which we are more certain, and which we can appeal to rationally support these empirical propositions.

${ }^{20}$ In OC $\$ 243$ Wittgenstein remarks, 'One says "I know’ when one is ready to give compelling grounds. 'I know" relates to a possibility of demonstrating the truth...But if what he believes is of such a kind that the grounds that he can give are no surer than his assertion, then he cannot say that he knows..."

${ }^{21}$ Cf. Pritchard (2012) for a critique of this account of the structure of reasons, in light of transmission and closure principles.

22 See here Stalnaker (1978: 88-89).

${ }^{23}$ For a helpful overview of Stalnaker's account, see Pagin (2012).
} 
is to attempt to do something that is already done." 24

Now, consider the conjecture that simple analytic truths will invariably be presuppositions of, and thus common ground, in any conversational context. Asserting a simple analytic truth, thus, will never cut down any live options. It follows that, with reference to Stalnaker's account of the role of assertion, it will always be pointless to assert a simple, analytic truth. ${ }^{25}$

The Stalnakerian point about the pragmatics of assertion - namely, don't assert what is already presupposed - might seem obvious ${ }^{26}$. However, in conjunction with a popular position about the epistemic norm that governs epistemically appropriate assertion, a further kind of explanation for our empirical results comes into focus. Consider the popular knowledge norm of assertion ${ }^{27}$, according to which knowledge is claimed as the epistemic credential that is necessary and sufficient for epistemically appropriate assertion. ${ }^{28}$

With reference to Stalnaker's pragmatic account, in conjunction with the knowledge norm of assertion, the following explanation now emerges: By the knowledge norm of assertion, if one has knowledge of simple analytic truths, then one's assertion of simple analytic truths is de facto epistemically appropriate. ${ }^{29}$ But, with reference to Stalnaker's pragmatic account of the role of assertion, all such assertions are fundamentally defective ${ }^{30}$, as assertions. They thus cannot be epistemically appropriate assertions, as they fail to be appropriate as assertions at all. ${ }^{31}$ By modus tollens, we therefore have reason to reject that

${ }^{24}$ See here Stalnaker (1978: 89).

${ }^{25}$ In fact, this conclusion resonates well with (early) pragmatist epistemologies. For Dewey, for instance, knowledge is the result of specific inquiries performed to resolve specific problems (Burke, 1994). In this sense, it is easy to see why analytic truths would fail to qualify as knowledge. For it is unclear which inquiries would be needed to come to know such truths and, in line with the Stalnakerian argument above, it is hard to see which specific problems they would help to solve (i.e., they are pointless). This is the reason why for Dewey mathematical truths do not qualify as knowledge, but are "postulates adopted because what follows from them" (Dewey, 1938, p. 144 ; quoted in Putnam, 2010, p. 41).

26 The Stalnakerian point aligns with Grice's (1989) maxim of quantity.and, to some extent, the maxim of relation.

${ }^{27}$ For some defenses of knowledge norms of assertion, see for instance Williamson (1996, 2000), DeRose (2002), Fricker (2006); Hawthorne (2004) and Stanley (2005). For a recent overview of the knowledge norm as well as other weaker norms, see [REFERENCE SUPPRESSED.]

${ }^{28}$ For instance, I might assert p on the basis of knowledge that p, while nonetheless being subject to moral criticism (perhaps $\mathrm{p}$ is offensive or cruel); or, alternatively, I might be criticized for asserting something misleading in that, while I know p and assert p, p conversationally implies q, and q is false. See here Grice (1957).

${ }^{29}$ Williamson's account can be contrasted with a weaker epistemic norms that govern assertion: the justification norm of assertion, according to which epistemic justification (e.g. rational support) is the relevant epistemic norm governing eistemically permissible assertion. See here Lackey (2007) and Douven (2005).

30 This is not to suggest that the speech acts are thereby not assertions. Rather, they are defective in that they fail to play a certain role that assertions as such aspire to - viz., the cutting down of live options.

${ }^{31}$ Indeed, for Stalnaker, such utterances fail to be assertions. Here's Stalnaker: "An assertion can be understood as a proposal to exclude from the possible situations compatible with the context those in which the proposition asserted is false" (Stalnaker 2004, 300). Cf. Milne (2012) for a helpful recent discussion here. 
such propositions are known (as, again, if they were, then it would be epistemically appropriate to assert them).

Note that empirical propositions won't have the property of being in principle presuppositions of any conversational context, even if they sometimes have this property ${ }^{32}$. Already this is enough for a plausible story for $\mathrm{H}$. The Stalnakerian account of the pragmatics of assertion in conjunction with the knowledge norm of assertion combine to offer a cogent story for why philosophers would be less likely to claim knowledge of analytic propositions than empirical propositions.

It is beyond the scope of the present article to assess or justify the philosophical explanations of $\mathrm{H}$ outlined above. We are not defending the Wittgenstenian account of rational support, nor Stalnaker's account of the pragmatics of assertion or the knowledge norm of assertion. All we wish to convince the reader of is that the empirical results we have found, though they run contrary to orthodox accounts of knowledge, are not without philosophical significance.

\subsection{Implications for Epistemology}

That experts are less willing to claim knowledge of simple and uncontroversial analytic $p$ 's than to empirical ones raises a number of worries for orthodox theories of knowledge, insofar as orthodox theories of knowledge hold that the conditions for knowing are 'contentindependent' in the sense described in Section 1 (e.g. determined exclusively by strength of epistemic position). The most substantial worry consistent with the experimental results is that content-independent theories of knowledge are false, in which case the ramification for mainstream epistemology would be severe: the schema $S$ knows that $p$ if and only if must be bifurcated in such a way that, for empirical propositions $p_{\mathrm{e}}$ and analytic propositions $p_{\mathrm{a}}$ the conditions for knowing $p_{\mathrm{e}}$ and $p_{\mathrm{a}}$ are different. By the lights of mainstream epistemology, this

32 Of course, we grant that the empirical propositions included in the surveys will in fact be presuppositions of most conversational contexts. Even so, varying one's interlocutors can create communication contexts where these empirical propositions are live, even among competent English speakers. But analytic truths, as such, are not live in conversational contexts with competent speakers. The fact that such propositions can never be live in this way renders them such that (at least, on the combination of the Stalnaker account and the knowledge account of assertion) they are unknowable (that is, on our modus tollens rationale), where as empirical propositions, despite their being presupposed in ordinary communication contexts, do not have this property. This difference could potentially explain a speaker's differentiation in attributing knowledge. Note though, to be clear, that the modus tollens argument is not being defended in the context of this paper as sound. Our point in this discussion section does not depend on either the Stalnakerian account of the pragmatics of assertion nor the knowledge norm of assertion being true. Rather, what we offered was at least two separate philosophical rationales which would be at least consistent with results that, as we've argued, are at tension with orthodox thinking about knowledge and the patterns of attribution that would be expected in light of it. Thanks to an anonymous referee for requesting clarification on this point. 
would be a devastating result ${ }^{33}$. However, it is incumbent on orthodox accounts of knowledge not willing to accept a bifurcated account to reconcile their position with the experimental results in some other way. In this respect, we take our data to have generated a kind of puzzle: to reject a conclusion that epistemologists will typically find undesirable, it is incumbent upon proponents of a more traditional picture of knowledge to provide a better explanation of the hypothesis. Below we consider and evaluate some of the available options and, interestingly, as we will see, none is very promising. This is, to reiterate, not an argument that the bifurcated account is best supported by the truth of the hypothesis - that would be to conclude far too much - but rather, an argument to the effect that the truth of our hypothesis raises challenges for one who wishes to reject a bifurcated account.

The bifurcated account could, of course, be avoided by orthodox content-independent theories of knowledge if a pragmatic explanation of the data can be offered. One way of offering such an explanation is to appeal to what has been described as tautology implicature:

The uttering of simple and obvious tautologies should, in principle, have absolutely no communicative import. However, utterances [like the following] can in fact convey a great deal.

..."War is war" [..."terrible things always happen in war, that's its nature and it's no good lamenting that particular disaster"]

..."Either John will come or he won't" [..."calm down, there's no point in worrying about whether he's going to come because there's nothing we can do about it"]

..."If he does it, he does it" [..."it's no concern of ours."] ${ }^{34}$

It seems plausible to think that utterances of tautologies would be conversationally appropriate only if such tautologies contain informative implicatures, and that this fact would generate a kind of expectation whereby, asserted tautologies elicit the expectation of some

\footnotetext{
${ }^{33}$ And, of course, this result would not be without its own problems. For one thing, consider that the very suggestion that the ascription variance captured by our results motivates 'separate conditions' for knowing simple analytic as opposed to empirical propositions would involve endorsing a proposal featuring more stringent conditions for knowing simple analytic truths. However, it is hard to see how more stringent conditions for knowing simple analytic truths would ever be satisfied; after all, as we discussed in Section 1, it is not clear how, if at all, one's epistemic position could be increased with respect to such propositions. So a skeptical problem threatens this move.

${ }^{34}$ Levinson (1983, 110-11), cited also in Davis (2012, 41-42).
} 
informative implicature, and then, we will be inclined to judge ourselves as knowing the tautology by assessing our epistemic standing vis-à-vis the tautology implicature rather than the tautology itself.

Consider the following example. A veteran of World War II might be more inclined to claim knowledge of the proposition "War is war" - where the veteran takes himself to have an excellent epistemic standing vis-à-vis the tautological implicature (e.g. ..."terrible things always happen in war, that's its nature and it's no good lamenting that particular disaster") while at the same time, finding himself less confident about "Invisible objects aren't visible" because he expects such a proposition would be asserted only if there is an informative implicature, and with respect to "Invisible objects aren't visible" judges himself as not knowing whatever the implicature would be.

We can see then that a pragmatic story materializes that would attempt to explain why the polled intuitions in the "Invisible objects aren't visible" example need not stand in tension with orthodox accounts of knowledge. With reference to tautology implicature, we can tell a story for why individuals polled would be hesitant to claim they know "Invisible objects aren't visible": they expect an implicature, are uncertain what such an implicature would be, and are thus unconfident about their standing to such an implicature.

Unfortunately for orthodox theories of knowledge, the problem with this explanation is that it would be capable of explaining away only a relatively small proportion of the observed differences. As can be seen in Tables 1 and 5, only a small subset of the analytic propositions in the survey could plausibly be argued to feature tautological implicature. It is hard to see how such a pragmatic story could explain away a sufficient amount of the data, even if it could explain away some of it. That said, it remains possible that a much more general pragmatic (e.g. Gricean) story could threaten to sever interesting inferences that can be drawn from the truth of the hypothesis our data supports to the matter of whether orthodox theories of knowledge are true ${ }^{35}$. We want to emphasise that, for our purposes - and as a note of clarification - the truth of our hypothesis (which we regard as interesting regardless of whether it ultimately offers good reason to embrace a heterodox theory of knowledge) puts

35 The most obvious such story would attempt to maintain an orthodox account of knowledge and simply add that what explains individuals' lack of willingness to attribute to themselves knowledge of analytic truths to the same extent as empirical truths is the Gricean maxim of informativeness. But on reflection it's hard to see how this story gets off the ground. To appreciate the difficulty, consider that while a Gricean informativeness maxim makes good sense of why one should not assert a simple analytic truth - as it will not be informative - the communicative purpose in claiming self-knowledge of an analytic truth (i.e. as in selfascribing such knowledge on a survey) is that of communicating whether one regards oneself as knowing the proposition in question. And this can be informative even if the simple communication of the analytic truth that features in the complement clause would not be. 
pressure on orthodox theories by offering not conclusive but rather defeasible evidence against the kind of attribution pattern one would expect were orthodox theories true. There is pressure on a proponent of the orthodox theory to vitiate this defeasible evidence by telling a compelling pragmatic story that diffuses this pressure on orthodox theories compellingly ${ }^{36}$.

Another strategy for trying to reconcile the experimental results with orthodox accounts of knowledge will be to make some rather significant concessions to the skeptic. This strategy insists that it is perfectly compatible with the survey results that we maintain a univocal (content-independent) analysis of knowledge but to then to insist that analytic propositions are such that our epistemic standing to them will not satisfy this univocal criterion. This move allows for orthodox accounts to continue the traditional project of supposing analyses of knowledge will be content-independent, even if whether one knows depends on whether the content is analytic or empirical.

As it turns out, this response will ultimately either (i) threaten wide-ranging scepticism, or (ii) require a rejection of the widely accepted closure principle:

Closure: If $\mathrm{S}$ knows that $\mathrm{p}$, and $\mathrm{S}$ knows that $\mathrm{p}$ entails q, then $\mathrm{S}$ knows that $\mathrm{q}$.

Note that every analytic truth that also qualifies as a logical truth is trivially entailed by every empirical truth. Therefore, by reference to the closure principle, failure to know analytic truths entails (by modus tollens) that we do not know the empirical truths that we know would entail them.

By ceding to the skeptic not only analytic truths but also the empirical truths we know would entail them, we have ceded far too much putative knowledge to the skeptic. The only way out, it seems, would be to deny the closure principle. But this is implausible. Either way, there is going to be a problem for this type of explanation of our data.

A third strategy for defenders of orthodox (content-independent) analyses of knowledge is to simply deny the philosophical and evidential significance of expert intuitions. ${ }^{37}$ A possible reason for doing so can be obtained by pointing out that if intuitions are to count as reliable data, there has to be more unanimity and less variation across different language groups than found in our study.

One problem with this line of argument is, however, that the intuitions we report vary

\footnotetext{
36 Thanks to an anonymous referee for raising this issue.

37 This is a conclusion drawn by e.g. Weinberg, Nichols \& Stich (2001); their claim, however, is entirely based on studies concerning non-expert subjects (and their intuitions).
} 
systematically across the population. ${ }^{38}$ As explained above, our statistical tests show that our results are not due to random variation. Our questions clearly measure some actually existing feature of the epistemic intuitions of the population. We take it that widespread expert intuitions are, at least prima facie, a proper foundation for philosophical theorising. ${ }^{39}$ In the absence of a competing explanation for why this is not so, we take it that the burden will remain on the proponent of orthodoxy to explain why the expert intuitions can be dismissed as a defective form of evidence about what analyses of knowledge should account for.

A fourth and final response is to question the methodology of our study. Here we anticipate two worries. The first relates to the fact that the set-up of our questionnaire, in which respondents are asked to judge a batch of both empirical and analytic propositions, may prompt contrastive thinking, and thus may artificially introduce a contrast between such propositions (even though it remains remarkable that the contrast actually runs counter to expectations).

A second worry is that participants' unwillingness to self-attribute knowledge of simple analytic truths in at least some of the cases might be explained with reference to their lack of mastery of some of some of the concepts that feature in the contents of the analytic truths. This point can be made, in particular, with reference to our question "There either is or isn't a largest prime number." Perhaps, as the worry goes, one who isn't confident what a prime number is might on this basis deny self-knowledge; or, one who is familiar with the concept might deny self-knowledge on the basis of lack of confidence whether the notion is welldefined $^{40}$. While this point is not without some concern, we think that even if lack of confidence with respect to a concept in question could have contributed to participants' unwillingness to self-attribute knowledge in the 'prime numbers' statement, such a lack of confidence would be an exception; while 'prime number' and perhaps also 'vixen' are concepts that some participants might regard themselves as lacking appropriate mastery of,

${ }^{38}$ A related strategy would involve raising the threshold for expertise. Relevant intuitions are those of expert intuiters, and to be an expert intuiter more is needed than: (i) having a formal training in philosophy; (ii) following current events in academic philosophy (by subscribing to a mailing-list for academic philosophers); and (iii) holding a Doctoral or Master's degree in philosophy. The tendencies we observed would be worrisome, so the objection goes, only if observed in a group consisting of prominent epistemologists (whatever that may mean), or preferably, given the language effect, very prominent epistemologists for whom English is their first language. This move, however, is tantamount to epistemic dogmatism - one narrows down the pool of experts to those who share or are willing to subscribe to one's own intuitions - and parochialism - one narrows down the pool of experts to those speaking one's own language. If this is what it takes to save content-independence, we decline. For apart from frustrating many able philosophers working outside epistemology and outside the Anglo-Saxon world, it would turn epistemology into quite a marginal phenomenon.

39 Such proper foundation view is also advocated by, for instance, Joshua Knobe (2003). For Knobe, however, the proper foundation isn't so much philosopher's intuitions as those of the philosophically untutored.

${ }^{40}$ Thanks to the editor for raising this point. 
we don't think it is likely that this phenomenon would extend to the majority of our cases of analytic truths, where the concepts featuring in the content of the proposition are straightforward and familiar ones.

A third worry concerns the very thin description of our cases, which in combination with the fact that respondents were not given the opportunity to explain the reasons for their judgment, makes it difficult to control for variables other than informational content of propositions (e.g., variables related to strength of epistemic position or to tautological implicature). Given the troubles of the first three responses, this fourth response may be the most promising for saving orthodox accounts of knowledge. Yet, it would require additional empirical research to substantiate this way out. So for the time being, we seem to have revealed a worrying tension that stands between the presuppositions of epistemological projects relying on the insight that knowledge should, uniformly, be a function of strength of epistemic position and, on the other hand, the intuitions reported by professional and nonprofessional philosophers about what claims they take themselves to actually know.

\section{REFERENGES}

Burke, T. (1994). Deweys New Logic: A Reply to Russell. Chicago: Chicago University Press. Dewey, J. (1938). Logic: The Theory of Inquiry. New York: Henry Holt and Company.

DeRose, K. (1992).Contextualism and Knowledge Attributions. Philosophy and Phenomenological Research, 52(4), 913-929.

- (2002). Assertion, knowledge, and context. Philosophical Review, 111, 167-203.

— (2009). The Case for Contextualism: Knowledge, Skepticism, and Context: Vol. 1. Oxford: Clarendon Press.

Fantl, J. \& McGrath, M. (2009). Knowledge in an Uncertain World. New York and Oxford: Oxford University Press.

Fricker, E. (2006). Second-hand knowledge. Philosophy and Phenomenological Research, 73, 592618.

Grice, H. P. (1957). Meaning. Philosophical Review, 66 (3), 377-388.

— (1989). Studies in the Way of Words. Harvard University Pres

Hawthorne, J. (2004). Knowledge and lotteries. Oxford: Oxford University Press.

Knobe, J., 2003. Intentional Action and Side Effects in Ordinary Language. Analysis, 63, 190193.

Krickeberg, K. (1965), Probability Theory, Addison-Wesley Pub. Co. 
MacFarlane, J. (2005). The Assessment Sensitivity of Knowledge Attributions. In T. Szabo Gendler J. Hawthorne (eds.) Oxford Studies in Epistemology Vol 1, 197-233.

- (2011). Relativism and knowledge attributions. In S. Bernecker and D. Pritchard (eds.) Routledge companion to epistemology, 536-544.

Milne, P. (2012). Belief, Degrees of Belief and Assertion. Dialectica, 66 (3), 331-349.

Pagin, Peter (2012) Assertion, In N. Zalta (ed.) The Stanford Encyclopedia of Philosophy (Winter 2012 Edition) URL = http://plato.stanford.edu/archives/win2012/entries/assertion/>.

Pritchard, D. (2012) Wittgenstein and the Groundlessness of our Believing. Synthese, $189,255-272$.

Putnam, R.A. (2010) Dewey's epistemology. In M. Cochran (ed.), The Cambridge Companion to Dewey, pp. 34-53. Cambridge: Cambridge University Press.

Russell, G. (2011). Truth in Virtue of Meaning: A Defence of the Analytic/Synthetic Distinction. Oxford: Oxford University Press.

Stalnaker, R. (1978). Assertion., in P. Cole (ed.), Syntax and Semantics 9, New York: New York Academic Press, 315-32; page reference is to the reprint in Stalnaker 1999.

— (2004). Assertion Revisited: On the Interpretation of Two-Dimensional Modal Semantics. Philosophical Studies, 118, 299-322.

Stanley, J. (2005). Knowledge and practical interests. Oxford: Oxford University Press.

Weinberg, J., Nichols, S. and S. Stich, 2001. Normativity and Epistemic Intuitions. Philosophical Topics, 29, 429-60

Williamson, T. (1996). Knowing and asserting. The Philosophical Review, 105, 489-523.

- (2000). Knowledge and its Limits. Oxford: Oxford University Press.

Wittgenstein, L. (1969). On Certainty. In G. E. M. Anscombe \& G. H. von Wright (Eds.), (trans: DPaul \& G. E. M. Anscombe). Oxford: Blackwell. 